\title{
Study on Radical Telomerization of Esters of Methacrylic Acid Using Bromotrichloromethane and Characteristics of the Resulting Telomers V. ${ }^{\dagger}$ Fluorenyl Methacrylates
}

\author{
Takao Kimura, Takuya Yoshimura, ${ }^{*}$ Hideo Morimoto, ${ }^{* *}$ \\ and Motome HAMASHIMA \\ Department of Environmental Chemistry, Faculty of Engineering, \\ Utsunomiya University, Ishii-cho, Utsunomiya 321, Japan
}

(Received April 8, 1987)

\begin{abstract}
The radical telomerization of 2-fluorenyl (2-FMA) and 9-fluorenyl (9-FMA) methacrylates was carried out using bromotrichloromethane as a telogen at 50,70 , and $90^{\circ} \mathrm{C}$. Despite no significant difference in the apparent rate of telomerization, the average degree of telomerization of 9-FMA was lower than that of 2-FMA regardless of the reaction temperature. Moreover, the telomerization of 9-FMA preferentially gave lactones with formation of 9bromofluorene. On the other hand, the telomerization of 2-FMA gave both the syndiotactic (st) and the isotactic dimeric telomers in a similar tacticity as that of most reseached monomers, but that of 9-FMA gave only st one. The 2-FMA telomers had a higher melting point than the 9-FMA homologues. The lactonization of dimeric and trimeric telomers was induced by the catalytic action of silica gel or heating. The 9-FMA telomers were greatly subject to lactonization in comparison with the 2-FMA ones, and the reactions of 2- and 9-FMA telomers, respectively, gave 2-hydroxyand 9-bromo-fluorenes as by-products.

KEY WORDS Bromotrichloromethane / Radical Telomerization / 2Fluorenyl Methacrylate / 9-Fluorenyl Methacrylate / Telomerization Behavior / Tacticity / Diastereoisomer / Lactonization of Telomer / Effect of Substituent /
\end{abstract}

Bromotrichloromethane (BTCM) is known to be an effective telogen for the radical telomerization of vinyl monomers by kinetic studies. ${ }^{1-5}$ The resulting telomers can be utilized as "reactive oligomers" by chemical modification of their functional groups. Furthermore, systematic reseach on the telomerization behavior of vinyl monomers with BTCM and characteristics of the telomers provide fundamental data in the field of high polymer chemistry.

In previous papers, ${ }^{6-9}$ we reported the radical telomerization of six kinds of alkyl $\left(\mathrm{C}_{1}-\mathrm{C}_{4}\right)$ and three kinds of aryl methacrylates using BTCM. The telomerization behavior of alkyl methacrylates and reactivity of the resulting telomers were greatly dependent on the degree of branching rather than the length of the alkyl chain. In particular, $t$-butyl methacrylate (TBMA) showed its own characteristics in many respects. On the other hand, the telomerization behavior of aryl methacrylates resembled that of primary alkyl methacrylates, but without formation of lactones. However, the apparent rate of telomerization $\left(R_{\mathrm{p}}{ }^{\prime}\right)$ of methacrylates was greatly dependent on the kinds of substituents in the ester group, the order of $R_{\mathrm{p}}{ }^{\prime}$ being alkyl $\geqq$ phenyl (PhMA) >

+ Part I-IV of this series are ref 6-9.

* Present address: Nara College of Education, Takahata-machi, Nara 630, Japan.

** Present address: Nippon Paint Co., Ltd., 19-17, Ikedanaka-machi, Neyagawa 572, Japan. 
1-naphthyl $\gg$ 2-naphthyl methacrylates. Furthermore, the aromatic and aliphatic telomers differed remarkably from each other in reactivity.

As a part of the study program, this paper describes the radical telomerization of 2-fluorenyl (2-FMA) and 9-fluorenyl (9-FMA) methacrylates using BTCM. Since the FMA monomers have a bulky aromatic ring, unique telomerization behavior similar to TBMA can be expected. The resulting telomers can be transformed into more useful oligomers by the introduction of functional groups into 2-, 7-, and 9-positions of the fluorene skeleton. Furthermore, the FMA telomers are favorable to elucidate the process of lactonization because they liberate a large-sized by-product containing the fluorenyl group in the lactonization. The effects of the position of fluorenyl substituents on the telomerization behavior and reactivity of the resulting telomers are discussed.

\section{EXPERIMENTAL}

\section{Measurements}

The same instruments and methods as described previously ${ }^{7}$ were used in this study.

\section{Materials}

The synthesis of monomers was carried out according to the reactions shown in Scheme 1. Using fluorene as a starting material, the intermediate derivatives were prepared according to the literature [2-nitrofluorene, ${ }^{10}$ 2aminofluorene, ${ }^{10}$ 2-hydroxyfluorene (8), ${ }^{11}$ 9-fluorenone, ${ }^{12}$ and 9-hydroxyfluorene ${ }^{13}$ ]. 2FMA and 9-FMA were synthesized from methacryloyl chloride and hydroxyfluorenes according to the procedure of Simionescu et al. ${ }^{14}$ 2-FMA was recrystallized from methanol-benzene $(4: 1), \mathrm{mp} 136.5-137.5^{\circ} \mathrm{C}$; yield $83 \%$; IR $1730(\mathrm{C}=\mathrm{O})$ and $1635 \mathrm{~cm}^{-1}(\mathrm{C}=\mathrm{C})$; ${ }^{1} \mathrm{H}$ NMR $\left(\mathrm{CDCl}_{3}\right) \delta 2.06\left(\mathrm{~s}, 3 \mathrm{H},-\mathrm{CH}_{3}\right), 3,86$ (s, 2H, 9- $\mathrm{H}$ in fluorene), $5.73\left(\mathrm{~m}, 1 \mathrm{H},=\mathrm{CH}_{\mathrm{a}}\right)$, $6.35\left(\mathrm{~s}, 1 \mathrm{H},=\mathrm{CH}_{\mathrm{b}}\right)$, and $6.97-8.00 \mathrm{ppm}(\mathrm{m}$,

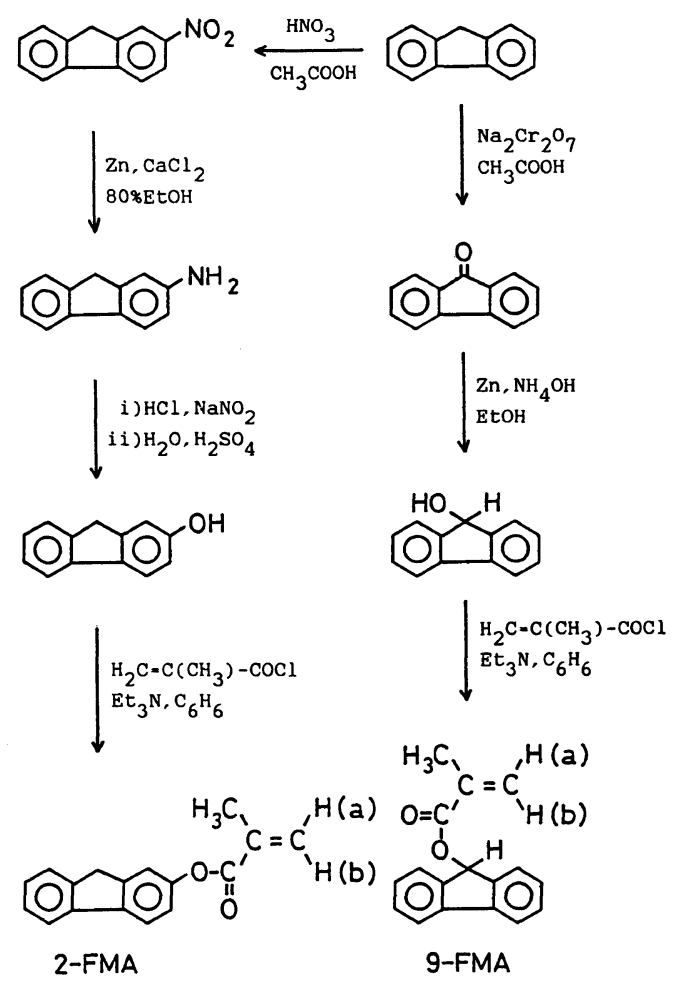

Scheme 1. Synthesis of monomers.

$7 \mathrm{H}$, aromatic protons). 9-FMA was recrystallized from methanol, mp $59-60.5^{\circ} \mathrm{C}$ (lit. ${ }^{15}$ $60-62 \mathrm{C}$ ); yield $89 \%$ (lit. ${ }^{15} 45 \%$ ); IR 1725 $(\mathrm{C}=\mathrm{O})$ and $1640 \mathrm{~cm}^{-1} \quad(\mathrm{C}=\mathrm{C}) ;{ }^{1} \mathrm{H}$ NMR $\left(\mathrm{CDCl}_{3}\right) \delta 1.99\left(\mathrm{~s}, 3 \mathrm{H},-\mathrm{CH}_{3}\right), 5.57(\mathrm{~m}, 1 \mathrm{H}$, $\left.=\mathrm{CH}_{\mathrm{a}}\right), 6.12\left(\mathrm{~s}, 1 \mathrm{H},=\mathrm{CH}_{\mathrm{b}}\right), 6.82(\mathrm{~s}, 1 \mathrm{H}, 9-\mathrm{H}$ in fluorene), and $7.07-8.00 \mathrm{ppm}(\mathrm{m}, 8 \mathrm{H}$, aromatic protons).

Commercial BTCM was distilled under reduced pressure before use, and 2,2'-azobisisobutyronitrile (AIBN) was recrystallized from methanol.

\section{Telomerization Procedure}

Telomerization was carried out at 50,70, and $90^{\circ} \mathrm{C}$ for 96,48 , and $24 \mathrm{~h}$, respectively, under the conditions of $[\mathrm{BTCM}]_{0} /[\mathrm{FMA}]_{0}=20$ and $[\mathrm{AIBN}]_{0}^{0.5} /[\mathrm{FMA}]_{0}=2$. The reaction mixture was treated in a similar manner as described in the previous paper. ${ }^{6}$ 


\section{Separation of Products}

The products were separated by column chromatography using Wakogel C-300 as packing material. The telomers were developed with 2:1-carbon tetrachloride : benzene as the eluent, and the eluting order was as follows: 1-mer (1)>syndiotactic (st) dimer (2a) $>$ isotactic dimer $(\mathbf{2 b})>s t$ trimer (3a). Strongly adsorbed components were further developed with 20:1-carbon tetrachloride:ethyl acetate as an eluent, and two dimeric lactones were eluted in the following order: $\mathbf{4 a}>\mathbf{4 b}$. Moreover, the separation of 9-FMA telomers afforded 9-bromofluorene (9) as a component more weakly adsorbed than $1, \mathrm{mp} 101-104^{\circ} \mathrm{C}$ (lit. ${ }^{13} 103-104^{\circ} \mathrm{C}$ ), and was identified using an authentic sample.

Identification of the series of telomers and lactones was carried out by a technique similar to that in the previous paper. ${ }^{6}$
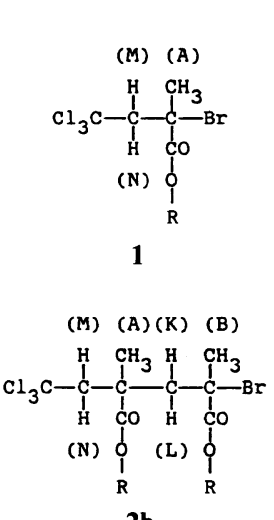

2b

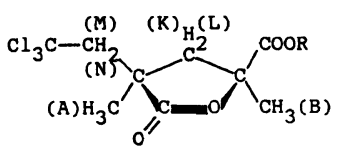

$\mathrm{R}=\mathrm{Fl}: \mathbf{4 a}$

$\mathrm{R}=\mathrm{H}: \mathbf{6 a}$

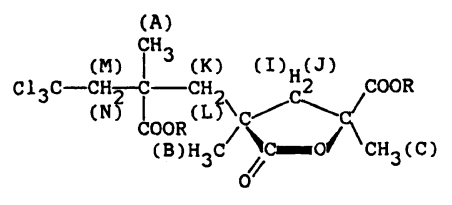

$\mathrm{R}=\mathrm{Fl}: \mathbf{5 a}$

$\mathrm{R}=\mathrm{H}: \mathbf{7 a}$
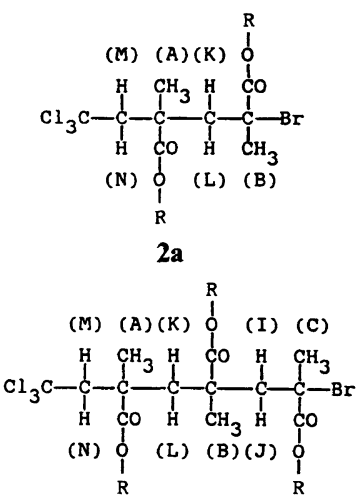

$3 \mathbf{a}$

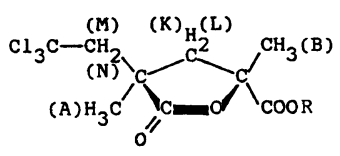

$4 b$

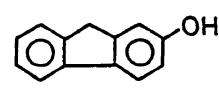

8

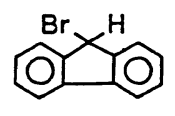

9

\section{Reactions of Telomers}

Catalytic Reaction with Silica Gel. To a solution of a telomer sample $(0.3 \mathrm{~g}$ in $9 \mathrm{ml}$ dry benzene), $3 \mathrm{~g}$ of silica gel (Wakogel C-300, dried at $180-200^{\circ} \mathrm{C}$ for $3 \mathrm{~h}$ ) were added, and the suspended mixture was stirred at $30^{\circ} \mathrm{C}$ for $72 \mathrm{~h}$. The reaction mixture was treated by the same method as described in the previous paper. ${ }^{7}$ The products were separated by silica gel column chromatography with $2: 1$-carbon tetrachloride:benzene as the eluent.

Pyrolysis. (a) Open System. A telomer sample was directly heated at $150^{\circ} \mathrm{C}$ for $2 \mathrm{~h}$. The products were separated in the same way as above, and when necessary, the following carboxylic acids were separated by extraction with $3 \%$ aqueous sodium hydroxide: 6a, mp $177-179^{\circ} \mathrm{C}(\mathrm{dec} .)^{7}$ and 7a, mp 201$204^{\circ} \mathrm{C}$ (dec.). ${ }^{9}$

(b) Closed System. Dimeric telomer 2a was sealed in a glass tube under reduced pressure, and heated at $150^{\circ} \mathrm{C}$ for $2 \mathrm{~h}$. The products were separated by the method described above.

\section{RESULTS AND DISCUSSION}

\section{Telomerization of Fluorenyl Methacrylates with BTCM}

Table I shows the results of the radical telomerization of 2-FMA and 9-FMA. Conventional telomerization was carried out at $50(24 \mathrm{~h}), 70(8 \mathrm{~h})$, and $90^{\circ} \mathrm{C}(4 \mathrm{~h})$ under the

Table I. Radical telomerization of fluorenyl methacrylates

\begin{tabular}{|c|c|c|c|c|c|}
\hline \multirow{2}{*}{ Monomer } & \multirow{2}{*}{$\frac{\text { Temp }}{{ }^{\circ} \mathrm{C}}$} & \multirow{2}{*}{$\frac{R_{\mathrm{p}}{ }^{\prime} \times 10^{6}}{\mathrm{~mol} \mathrm{l}^{-1} \mathrm{~s}^{-1}}$} & \multicolumn{3}{|c|}{$\mathrm{MWD} / \mathrm{wt} \%$} \\
\hline & & & $n=1$ & $n=2^{\mathrm{a}}$ & $n \geqq 3$ \\
\hline \multirow{3}{*}{ 2-FMA } & 50 & 2 & 9 & $15[0]$ & 76 \\
\hline & 70 & 4 & 25 & $24[2]$ & 51 \\
\hline & 90 & 9 & 27 & 23 [ 3] & 50 \\
\hline \multirow{3}{*}{ 9-FMA } & 50 & 2 & 31 & $36[10]$ & 33 \\
\hline & 70 & 5 & 40 & $35[20]$ & 25 \\
\hline & 90 & 9 & 48 & 34 [29] & 18 \\
\hline
\end{tabular}

a [ ], content of dimeric lactones. 
conditions of $[\mathrm{BTCM}]_{0} /[\text { Monomer }]_{0}=8$ and $[\mathrm{AIBN}]_{0}^{0.5} /[\text { Monomer }]_{0}=0.5$ as described in our previous papers. ${ }^{6-9}$ It was confirmed by GPC analysis that the telomerization of 9FMA showed desirable product distribution (MWD), except for the slight survival of monomer, while the telomerization of 2-FMA gave exclusively oligomers higher than the trimer together with a lot of unreacted monomer. Therefore, the telomerization behavior of two FMA monomers was compared under more drastic conditions as described in the experimental part. As shown in Table $\mathrm{I}, R_{\mathrm{p}}{ }^{\prime}$ was not appreciably dependent on the position of fluorenyl substituents in the ester group. However, if the excess of reaction time is taken into account, the true rate of telomerization of 9-FMA is considered higher than that of 2FMA. On the other hand, the average degree of telomerization $(\bar{n})$ of 9-FMA was lower than that of 2-FMA regardless of the reaction temperature. Therefore, it was found that the resulting telomeric radical from 9-FMA is apt to cause the chain transfer reaction to BTCM than that from 2-FMA under similar telomerization conditions. Moreover, the telomerization of 9-FMA preferentially gave lactones with the formation of 9 , and the yield of lactones gradually increased with increasing reaction temperature.

\section{Identification of Telomers and Lactones}

The characterizations of the homologous telomers and lactones are listed in Tables II and III. The 2-FMA homologues had a higher melting point than the 9-FMA ones. Similarly, the IR absorption maxima of $\mathrm{C}=\mathrm{O}$ stretching vibration of the 2-FMA homologues appeared at a higher wavenumber relative to the corresponding absorption maxima of the 9-FMA ones. The different fragmentation ion peaks were detected in the mass spectra of the 2- and 9-FMA homologues. That is, the spectra of 2-FMA homologues gave preferentially 2-fluorenyloxy ion peak, whereas those of 9FMA ones, 9-fluorenyl ion peak. The ${ }^{1} \mathrm{H}$ NMR parameters of the homologous telomers and lactones are summarized in Tables IV and V. All methyl- and methylene-proton signals of the 9-FMA homologues resonated in higher magnetic fields relative to the corresponding proton signals of the 2-FMA ones. This reg-

Table II. Characterization of telomers

\begin{tabular}{|c|c|c|c|c|}
\hline \multirow{2}{*}{ Telomer } & \multirow{2}{*}{$\mathbf{R}^{\mathbf{a}}$} & $\mathrm{mp}$ & $v(\mathrm{C}=\mathrm{O})$ & \multirow{2}{*}{$m / z\left(\mathrm{QM}^{+}\right)$} \\
\hline & & ${ }^{\circ} \mathrm{C}$ & $\mathrm{cm}^{-1}$ & \\
\hline \multirow{2}{*}{1} & $2-\mathrm{Fl}$ & $187.5-189.5^{b}$ & 1755 & 447 \\
\hline & 9-Fl & $115-117^{\mathrm{c}}$ & 1730 & 447 \\
\hline \multirow{2}{*}{$\mathbf{2 a}$} & $2-\mathrm{Fl}$ & $180-181(\text { dec. })^{b}$ & 1755,1740 & $(697)^{\mathrm{e}}$ \\
\hline & 9-Fl & $151.5-153 \quad(\mathrm{dec} .)^{\mathrm{c}}$ & 1730,1720 & $(697)^{e}$ \\
\hline \multirow{2}{*}{ 2b } & $2-\mathrm{Fl}$ & $173-175.5(\mathrm{dec} .)^{\mathrm{b}}$ & 1775,1760 & $(697)^{e}$ \\
\hline & $9-\mathrm{Fl}$ & & & \\
\hline \multirow{2}{*}{ 3a } & $2-\mathrm{Fl}$ & $225-227.5(\mathrm{dec} .)^{\mathrm{d}}$ & 1755 & $-\mathrm{f}$ \\
\hline & 9-Fl & $157-169 \quad(\mathrm{dec} .)^{\mathrm{c}}$ & 1730 & $-\mathrm{f}$ \\
\hline
\end{tabular}

a Fl, fluorenyl.

b Recrystallized from benzene.

c Recrystallized from carbon tetrachloride.

d Recrystallized from pyridine.

e No parent ion peak was detected.

f Not measured. 
Telomerization of Fluorenyl Methacrylates by BTCM

Table III. Characterization of lactones

\begin{tabular}{|c|c|c|c|c|}
\hline \multirow{2}{*}{ Lactone } & \multirow{2}{*}{$\mathbf{R}^{\mathbf{a}}$} & $\mathrm{mp}$ & $v(\mathrm{C}=\mathrm{O})$ & \multirow{2}{*}{$m / z\left(\mathrm{QM}^{+}\right)$} \\
\hline & & ${ }^{\circ} \mathrm{C}$ & $\mathrm{cm}^{-1}$ & \\
\hline \multirow{2}{*}{$\mathbf{4 a}$} & $2-\mathrm{Fl}$ & $179.5-181.5(\mathrm{dec} .)^{\mathrm{b}}$ & 1790,1765 & 453 \\
\hline & 9-Fl & $107-108.5(\mathrm{dec} .)^{\mathrm{b}}$ & 1775,1745 & 453 \\
\hline \multirow{2}{*}{ 4b } & $2-\mathrm{Fl}$ & $161-162.5(\mathrm{dec} .)^{\mathrm{b}}$ & 1775,1760 & 453 \\
\hline & $9-\mathrm{Fl}$ & $95.5-97.5(\mathrm{dec} .)^{\mathfrak{c}}$ & 1780,1745 & 453 \\
\hline \multirow{2}{*}{$5 \mathbf{a}$} & $2-\mathrm{Fl}$ & & & \\
\hline & 9-Fl & $161-162.5(\mathrm{dec} .)^{\mathrm{c}}$ & 1785,1735 & $-^{\mathrm{d}}$ \\
\hline
\end{tabular}

a See Table II.

b Recrystallized from carbon tetrachloride.

c Recrystallized from 4: 1-carbon tetrachloride : hexane.

d Not measured.

Table IV. ${ }^{1} \mathrm{H}$ NMR parameters of telomers in $\mathrm{CDCl}_{3}$

\begin{tabular}{|c|c|c|c|c|}
\hline \multirow{2}{*}{ Telomer } & \multirow{2}{*}{ Proton } & \multirow{2}{*}{ Symbol } & \multicolumn{2}{|c|}{ Chemical shift $\delta /$ ppm } \\
\hline & & & 2-FMA & 9-FMA \\
\hline \multirow{2}{*}{1} & $-\mathrm{CH}_{3}$ & A & 2.34 & 2.29 \\
\hline & $-\mathrm{CH}_{2}-$ & $\mathbf{M}, \mathbf{N}$ & $\begin{array}{c}4.41 \quad 3.65 \\
(15.0)^{\mathrm{a}}\end{array}$ & $\begin{array}{c}4.33 \quad 3.58 \\
(15.6)\end{array}$ \\
\hline \multirow{4}{*}{$\mathbf{2 a}$} & $-\mathrm{CH}_{3}$ & A & \multirow{2}{*}{$\begin{array}{l}2.26 \\
1.71\end{array}$} & \multirow{2}{*}{$\begin{array}{l}1.97 \\
1.47\end{array}$} \\
\hline & $-\mathrm{CH}_{3}$ & B & & \\
\hline & $-\mathrm{CH}_{2-}^{-}$ & $\mathrm{K}, \mathrm{L}$ & $\begin{array}{cc}3.28 & 2.95 \\
(13.8)\end{array}$ & $\begin{array}{c}3.03 \quad 2.76 \\
(14.4)\end{array}$ \\
\hline & $-\mathrm{CH}_{2}-$ & $\mathrm{M}, \mathrm{N}$ & $\begin{array}{c}3.90 \quad 3.07 \\
(15.0)\end{array}$ & $\begin{array}{c}3.65 \quad 2.90 \\
(15.0)\end{array}$ \\
\hline \multirow{4}{*}{ 2b } & $-\mathrm{CH}_{3}$ & A & \multirow{2}{*}{$\begin{array}{l}2.28 \\
1.87\end{array}$} & \\
\hline & $-\mathrm{CH}_{3}$ & B & & \\
\hline & $-\mathrm{CH}_{2-}$ & $\mathrm{K}, \mathrm{L}$ & $(15.0)$ & \\
\hline & $-\mathrm{CH}_{2}-$ & $\mathrm{M}, \mathrm{N}$ & $\begin{array}{c}3.893 .17 \\
(15.0)\end{array}$ & \\
\hline \multirow{6}{*}{$\mathbf{3 a}$} & $-\mathrm{CH}_{3}$ & A & $-^{b}$ & 1.92 \\
\hline & $-\mathrm{CH}_{3}$ & B & - & 1.20 \\
\hline & $-\mathrm{CH}_{3}$ & C & - & 1.49 \\
\hline & $-\mathrm{CH}_{2}-$ & $\mathbf{I}, \mathbf{J}$ & - & $\begin{array}{c}2.99 \quad 2.75 \\
(13.8)\end{array}$ \\
\hline & $-\mathrm{CH}_{2}-$ & $\mathrm{K}, \mathrm{L}$ & - & 2.22 \\
\hline & $-\mathrm{CH}_{2}-$ & $\mathrm{M}, \mathrm{N}$ & - & $\begin{array}{c}3.53 \quad 2.81 \\
(15.0)\end{array}$ \\
\hline
\end{tabular}

a ( ), coupling const. $J$ in $\mathrm{Hz}$.

b Measurement of 3a $(\mathrm{R}=2-\mathrm{Fl})$ was not possible.
Table V. ${ }^{1} \mathrm{H}$ NMR parameters of lactones in $\mathrm{CDCl}_{3}$

\begin{tabular}{|c|c|c|c|c|}
\hline \multirow{2}{*}{ Lactone } & \multirow{2}{*}{ Proton } & \multirow{2}{*}{ Symbol- } & \multicolumn{2}{|c|}{ Chemical shift $\delta / \mathrm{ppm}$} \\
\hline & & & 2-FMA & 9-FMA \\
\hline \multirow{5}{*}{$4 a$} & $-\mathrm{CH}_{3}$ & A & 1.88 & 1.75 \\
\hline & $-\mathrm{CH}_{3}$ & B & 1.48 & 1.38 \\
\hline & $-\mathrm{CH}_{2-}$ & $\mathrm{K}, \mathrm{L}$ & 2.97 & $2.94 \quad 2.67$ \\
\hline & & & & $(14.4)^{\mathrm{a}}$ \\
\hline & $-\mathrm{CH}_{2-}$ & $\mathrm{M}, \mathrm{N}$ & $\begin{array}{c}3.48 \quad 3.13 \\
(15.6)\end{array}$ & $\begin{array}{c}3.41 \quad 3.06 \\
(15.6)\end{array}$ \\
\hline \multirow{4}{*}{$4 b$} & $-\mathrm{CH}_{3}$ & A & 1.89 & 1.74 \\
\hline & $-\mathrm{CH}_{3}$ & B & 1.60 & 1.50 \\
\hline & $-\mathrm{CH}_{2}-$ & $\mathrm{K}, \mathrm{L}$ & $\begin{array}{c}3.64 \quad 2.29 \\
(15.0)\end{array}$ & $\begin{array}{c}3.40 \quad 2.10 \\
(15.0)\end{array}$ \\
\hline & $-\mathrm{CH}_{2}-$ & $\mathrm{M}, \mathrm{N}$ & $\begin{array}{c}3.45 \quad 3.17 \\
(15.0)\end{array}$ & $\begin{array}{c}3.31 \quad 3.02 \\
(15.0)\end{array}$ \\
\hline \multirow{6}{*}{$5 \mathbf{a}$} & $-\mathrm{CH}_{3}$ & A & & 1.66 \\
\hline & $-\mathrm{CH}_{3}$ & B & & 1.41 \\
\hline & $-\mathrm{CH}_{3}$ & $\mathrm{C}$ & & 1.34 \\
\hline & $-\mathrm{CH}_{2}-$ & $\mathrm{I}, \mathrm{J}$ & & 2.03 \\
\hline & $-\mathrm{CH}_{2}-$ & $\mathrm{K}, \mathrm{L}$ & & $\begin{array}{c}2.53 \quad 2.05 \\
(13.2)\end{array}$ \\
\hline & $-\mathrm{CH}_{2}-$ & $\mathrm{M}, \mathrm{N}$ & & $\begin{array}{c}3.76 \quad 3.00 \\
(15.6)\end{array}$ \\
\hline
\end{tabular}

ular shift is attributable to differences in the shielding effect of the fluorenyl groups. The proton signals of the fluorenyl groups, which 
Table VI. Ratios of dimeric diasteroisomers in the products

\begin{tabular}{|c|c|c|c|c|c|c|c|}
\hline \multirow{2}{*}{$\begin{array}{c}\text { Mono- } \\
\text { mer }\end{array}$} & \multirow{2}{*}{$\frac{\text { Temp }}{{ }^{\circ} \mathrm{C}}$} & \multicolumn{2}{|c|}{$\%$} & \multicolumn{2}{|c|}{$\%$} & \multicolumn{2}{|c|}{$\%$} \\
\hline & & $2 a$ & $\mathbf{2 b}$ & $4 a$ & $4 b$ & $2 a+4 a$ & $2 b+4 b$ \\
\hline \multirow{3}{*}{ 2-FMA } & 50 & 80 & 20 & - & - & 80 & 20 \\
\hline & 70 & 74 & 26 & 100 & 0 & 78 & 22 \\
\hline & 90 & 73 & 27 & 100 & 0 & 79 & 21 \\
\hline \multirow{3}{*}{ 9-FMA } & 50 & 100 & 0 & 0 & 100 & 63 & 37 \\
\hline & 70 & 100 & 0 & 25 & 75 & 50 & 50 \\
\hline & 90 & 100 & 0 & 45 & 55 & 50 & 50 \\
\hline
\end{tabular}

are omitted in the tables, appeared in the expected resonance regions.

\section{Ratios of Dimeric Diastereoisomers in the Products}

Table VI shows the ratio of two dimeric diastereoisomers obtained in the telomerization of two FMA monomers. The telomerization of 2-FMA gave $2 \mathbf{a}(\mathrm{R}=2-\mathrm{Fl})$ in preference to $\mathbf{2 b}(\mathrm{R}=2-\mathrm{Fl})$ in a similar ratio as that of conventional monomers such as methyl or naphthyl (NMA) methacrylates, whereas the telomerization of 9-FMA gave only $\mathbf{2 a}$ $(\mathrm{R}=9-\mathrm{F} 1)$ just as that of TBMA. The formation of the two lactones, $4 \mathbf{a}$ and $\mathbf{4 b}$, should not be neglected for the purpose of estimating more refined tacticity. The conversion of $\mathbf{2 a}$ into $\mathbf{4 a}$, while that of $\mathbf{2 b}$ into $\mathbf{4 b}$, is induced by the heat of telomerization, through lactonization as will be described later. Consequently, the yield of $(\mathbf{2} \mathbf{a}+\mathbf{4 a})$ was larger than that of $(2 b+4 b)$ as shown in Table VI, but the production ratio of $(2 b+4 b)$ to $(2 a+4 a)$ in the telomerization of 9-FMA increased to $50: 50$ at a reaction temperature above $70^{\circ} \mathrm{C}$. The telomerization of 9-FMA had a great resemblance to that of TBMA in tacticity.

\section{Reactivity of Telomers}

Catalytic Reaction with Silica Gel. The lactonization of dimeric telomers was induced by the catalytic action of silica gel as shown in Table VII. In the same manner as conven-
Table VII. Catalytic reactions of dimeric telomers with silica gel

\begin{tabular}{|c|c|c|c|c|}
\hline \multirow{2}{*}{ Telomer } & \multirow{2}{*}{$\mathrm{R}^{\mathrm{a}}$} & \multicolumn{2}{|c|}{ Yield of products $/ \%$} & \multirow{2}{*}{$\frac{\text { Recovd }}{\%}$} \\
\hline & & $4 a$ & $4 b$ & \\
\hline \multirow{3}{*}{$2 a$} & $2-\mathrm{Fl}$ & - & - & 100 \\
\hline & 9-Fl & 54 & - & 46 \\
\hline & $2-\mathrm{Fl}^{\mathrm{b}}$ & 89 & - & 11 \\
\hline 2b & $2-\mathrm{Fl}^{\mathrm{b}}$ & - & 100 & - \\
\hline
\end{tabular}

a See Table II.

b Sample, $0.3 \mathrm{~g} /$ silica gel, $100 \mathrm{~g} /$ benzene, $300 \mathrm{ml}$.

Table VIII. Pyrolysis of dimeric telomers

\begin{tabular}{|c|c|c|c|c|c|c|}
\hline \multirow{2}{*}{ Telomer } & \multirow{2}{*}{$\mathrm{R}^{\mathrm{a}}$} & \multirow{2}{*}{$\begin{array}{l}\text { Condi- } \\
\text { tion }^{\mathrm{b}}\end{array}$} & \multicolumn{3}{|c|}{$\begin{array}{c}\text { Yield of } \\
\text { products } / \%\end{array}$} & \multirow{2}{*}{$\frac{\text { Recovd. }}{\%}$} \\
\hline & & & $\mathbf{4 a}$ & $4 b$ & $6 a$ & \\
\hline \multirow{6}{*}{$2 \mathbf{a}$} & & i) & - & - & - & 100 \\
\hline & $2-\mathrm{Fl}$ & ii) & 39 & - & - & 61 \\
\hline & & i) ${ }^{c}$ & - & - & 100 & - \\
\hline & & i) & 74 & - & 26 & - \\
\hline & 9-Fl & ii) & 76 & - & 24 & - \\
\hline & & i) ${ }^{c}$ & 10 & - & 86 & - \\
\hline $2 \mathbf{b}$ & $2-\mathrm{Fl}$ & ii) & - & 73 & - & 27 \\
\hline
\end{tabular}

a See Table II.

b i) closed system; ii) open system.

c 10 times molar water was added.

tional dimeric telomers already studied, this reaction selectively proceeded by the following routes: $\mathbf{2 a} \rightarrow \mathbf{4 a}$ and $\mathbf{2 b} \rightarrow \mathbf{4 b}$, and the conversion yield of $\mathbf{2 b}$ was greater than that of $\mathbf{2 a}$. However, the lactonization of $2 a(R=2-F 1)$ was considerably inferior to that of $2 a(R=9$ $\mathrm{F} 1)$ in lactone yields. Under similar conditions, the reactivity of $\mathbf{2 a}$ increased in the order: $\mathrm{R}=\operatorname{alkyl}(86-100 \%)>9-\mathrm{F} 1(54 \%)>$ naphthyl $(23-48 \%)>$ phenyl $(21 \%)>2-\mathrm{F} 1(0 \%)$. Moreover, the resulting elimination product by the intramolecular cyclization of dimeric telomers was isolated as a stable by-product. That is, the reaction of $2 \mathbf{a}(\mathrm{R}=2-\mathrm{F} 1)$ and $\mathbf{2 b}$ $(R=2-F 1)$ gave a roughly equimolar amount 
of 8 with the lactone, whereas that of $\mathbf{2 a}$ $(\mathrm{R}=9-\mathrm{F} 1)$ gave a corresponding amount of 9 . Similarly, the reaction of $\mathbf{3 a}(\mathrm{R}=9-\mathrm{F} 1)$ gave trimeric lactone $5 \mathbf{a}(\mathrm{R}=9-\mathrm{F} 1)$ in a $38 \%$ yields, and a roughly equimolar amount of 9 was simultaneously obtained. However, the lactonization of $3 a(R=2-F 1)$ with silica gel was hard because of its poor solubility in benzene as a solvent.

Pyrolysis. The FMA dimeric telomers, like the NMA ones, underwent an intense damage under heating at $200^{\circ} \mathrm{C}$ in the absence of solvent. Therefore, the pyrolysis of dimeric telomers was attempted at $150^{\circ} \mathrm{C}$ as shown in Table VIII. Heating of $\mathbf{2 a}$ and $\mathbf{2} \mathbf{b}$ gave corresponding lactones and by-products by the same route as the catalytic lactonization with silica gel. Under similar conditions, the reactivity of lactonization increased as follows: $\mathbf{2 a}(\mathrm{R}=9-\mathrm{F} 1) \gg \mathbf{2 b}(\mathrm{R}=2-\mathrm{F} 1)>\mathbf{2 a}(\mathrm{R}=2-$ $\mathrm{F} 1)$. Furthermore, the resulting lactone $4 \mathbf{a}$ $(\mathrm{R}=9-\mathrm{F} 1)$ was partly transformed into carboxylic acid 6a through the pyrolysis of $\mathbf{2 a}$ $(\mathrm{R}=9-\mathrm{F} 1)$. Similarly, the pyrolysis of $\mathbf{3 a}$ $(\mathrm{R}=9-\mathrm{F} 1)$ in an open system gave $40 \%$ of $5 \mathbf{a}$ $(\mathrm{R}=9-\mathrm{F} 1)$ and $28 \%$ of dibasic acid $7 \mathbf{a}$, and a corresponding amount of 9 was simultaneously obtained. On the other hand, the lactonization of $3 \mathbf{a}(\mathrm{R}=2-\mathrm{F} 1)$, which has a higher melting point than 3a $(R=9-F 1)$, was not observed under the same conditions.

\section{Mechanistic Consideration of Lactonization}

Judging from the fragmentation pattern of fluorenyl ester group detected in the mass spectra and the structure of the by-product obtained in lactonization, it was found that 2FMA telomers were subject to $\alpha$-cleavage of the fluorenyl ester group through lactonization, and that for 9-FMA ones, ionic cleavage occurred between the ethereal oxygen atom and the 9-positional carbon atom of the fluorenyl ester group. As can be seen from Table VIII, the lactonization of $2 \mathbf{a}(\mathrm{R}=2-\mathrm{F} 1)$ was apparently promoted in the presence of water, while that of $2 \mathbf{a}(\mathrm{R}=9-\mathrm{F} 1)$ was not very

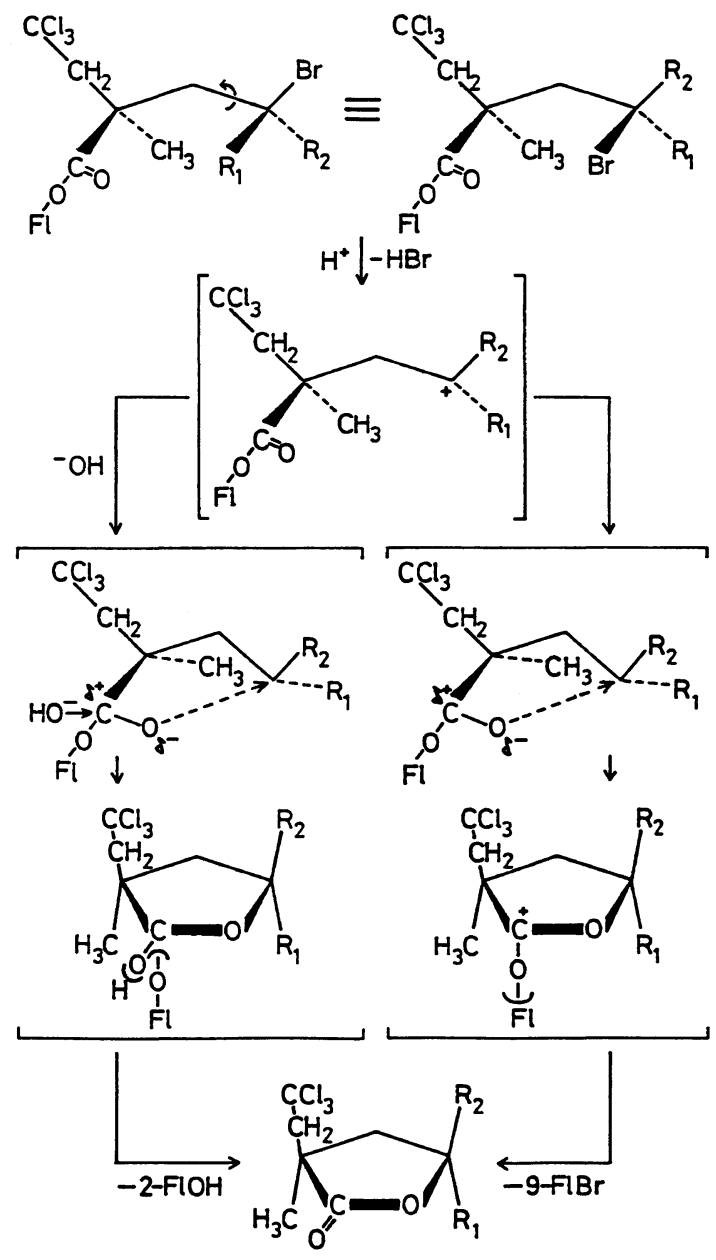

Scheme 2. Mechanisms of lactonization.

susceptible to water. The evolution of hydrogen bromide was only observed in the pyrolysis of $2 \mathbf{a}(\mathrm{R}=2-\mathrm{F} 1)$ and $2 \mathbf{b}(\mathrm{R}=2-\mathrm{F} 1)$. Therefore, the lactonization of 2- and 9-FMA telomers is expected to proceed by dissimilar routes as shown in Scheme 2. The lactonization of 2-FMA telomers is considered to take place by a $S_{N} i$ mechanism with the nucleophilic addition of the hydroxyl anion against the ester group and the liberation of the 2fluorenyloxy anion, in analogy with that of the resulting aromatic telomers from PhMA or NMA. On the other hand, the lactonization of 9-FMA telomers is considered to take place by 
a simple $\mathrm{S}_{N} \mathrm{i}$ mechanism as discussed in the previous paper, ${ }^{7}$ in analogy with that of the resulting aliphatic telomers from alkyl methacrylates.

\section{REFERENCES}

1. C. A. Barson, R. R. Mather, and J. C. Robb, Trans. Faraday Soc., 66, 2585 (1970).

2. D. A. J. Harker, R. A. M. Thomson, and I. R. Walters, Trans. Faraday Soc., 67, 3057 (1971).

3. C. A. Barson, A. R. Luxton, and J. C. Robb, J. Chem. Soc., Faraday Trans. 1, 68, 1666 (1972).

4. C. A. Barson, R. A. Batten, and J. C. Robb, Eur. Polym. J., 10, 97 (1974).

5. C. A. Barson and R. Ensor, Eur. Polym. J., 13, 53 (1977).

6. T. Kimura, T. Kodaira, and M. Hamashima, Polym. J., 15, 293 (1983).
7. T. Kimura and M. Hamashima, Polym. J., 18, 21 (1986).

8. T. Kimura, I. Nakanishi, and M. Hamashima, Polym. J., 18, 689 (1986).

9. T. Kimura, H. Tasaka, and M. Hamashima, Polym. J., 19, 305 (1987).

10. W. E. Kuhn, Org. Synth., Coll. Vol. II, 447 (1943).

11. F. E. Ray and C. F. Hull, J. Org. Chem., 14, 349 (1949).

12. N. Ishikawa and T. Ozawa, "Yukikagoubutsu Gouseihou," Vol. 11, The Society of Synthetic Organic Chemistry, Japan, Ed., Gihoudou, Tokyo, 1959, pp 93-96.

13. K. Suzuki, "Yukikagoubutsu Gouseihou," Vol. 11, The Society of Synthetic Organic Chemistry, Japan, Ed., Gihoudou, Tokyo, 1959, pp 18-20.

14. C. I. Simionescu and V. Percec, Polym. Bull., 2, 51 (1980).

15. J. Nishino, H. Nakahata, and Y. Sakaguchi, Polym. J., 2, 555 (1971). 